\title{
Estimation of the Effect of Lift-drag Ratio caused by Relaxing Longitudinal Static Stability of a certain-type of Joined-Wing Aircraft
}

\author{
Zhen Liang ${ }^{a}$, Weijun Wang ${ }^{b}$ \\ School of Aeronautic Science and Engineering, Beihang University, Beijing 100000, China. \\ awherermywings@163.com, bwangwj@buaa.edu.cn
}

Keywords: Joined-wing aircraft, Relaxing static stability, Lift-drag ratio.

\begin{abstract}
According to a given joined-wing aircraft, based on the DATCOM calculation data, under typical cruise and stable hover flight conditions, cases are considered with and without the relaxation of static stability technique. The actual lift-drag ratio of the joined-wing layout and conventional layout is compared and the difference is revealed. This proceeding analyses the reason, seeking the pattern, providing the foundation for the optimization of the overall program of the aircraft in the future.
\end{abstract}

\section{Introduction}

Joined-wing aircraft consists of a front wing and a rear wing. Front wing is swept back, and rear wing is swept forward. Rear wing and front wing join at the wingtip or the middle of front wing, forming a frame structure. Compared with the conventional layout, the joined-wing layout has many advantages, such as: lighter weight; higher stiffness; smaller induced resistance; better transonic area distribution; higher maximum trim lift coefficient; smaller wetted area; direct lift and direct side force control; better stability and handling. However, due to the absence of a tailplane far away from the centre of gravity, which the conventional aircrafts usually have, the tail capacity of the rear wings of the joined-wing layout is smaller in the whole aircraft trim calculation. The trim capacity is weaker and the trim loss is larger.[1]

The lift-drag ratio is one of the most important aerodynamic characteristics of the aircraft, which determines the flight performance of the aircraft from the aerodynamic point of view, such as the aircraft's range, stable circling overload and so on. Relaxing the longitudinal static stability is the basic elements in the Control Figured concept. It is effective in improving the lift-drag ratio after trimming. For the joined-wing layout and conventional layout, the same technique of relaxing the longitudinal static stability is adopted, and the lift-drag ratio gain obtained is greatly different. Because the relaxation of longitudinal static stability technique is adopted, higher requirement of the controlling system is needed, e.g. smaller non-sensitive areas and higher speed of the rudder loop, and we need sacrifice some performance to meet our target. It is of great significance to weigh these factors to obtain the satisfying result.[2]

Based on the DATCOM calculation data, under typical cruise and stable hover flight conditions, cases are considered with and without the relaxation of static stability technique. The actual lift-drag ratio of the joined-wing layout and conventional layout is compared and the difference is revealed. This proceeding analyses the reason, seeking the pattern, providing the foundation for the optimization of the overall program of the aircraft in the future.[3]

\section{Layout Introduction}

A certain type of joined-wing layout aircraft and a conventional layout are selected as comparative models, which in this proceeding set up using DATCOM ; In a typical Mach number, under typical conditions of the longitudinal static stability, the aircraft is trimmed and the lift-drag ratio characteristic is analysed. 

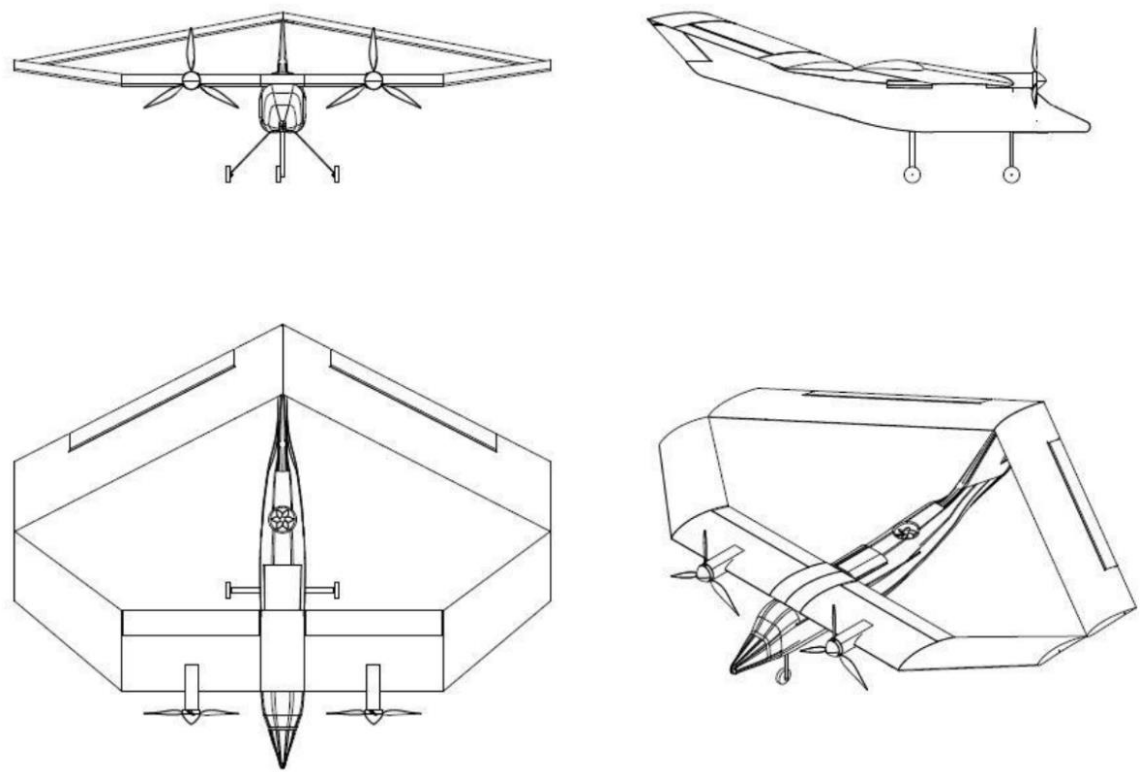

Fig. 1 Three-dimensional view of a certain type of wing aircraft

This joined-wing layout design aircraft is a low-speed general civilian aircraft. In addition to its excellent cruising performance, it also has vertical / short take-off and landing capabilities to facilitate future use in densely populated areas such as cities.[4]

In the design of this joined-wing layout, the "negative staggered" configuration is used, i.e. the low front wing, high rear wing. The inner section of the wing is straight and used to install two power units. Flat straight span airship flaps use double-slit flaps, the slipstream of the propeller covers most of the front wing aerofoils and the trailing edge flaps of the front wings. The high-speed slipstream of the propellers effectively improves the efficiency of the wings and flaps, i.e., the power increase. In the middle of the fuselage behind we adopt a ducted engine layout, to provide upward tension in the vertical take-off and landing mode, to achieve hover and short take-off and landing capability.

When short take-off flap large angle deflection, both maximum engine thrust, a high-speed propeller slipstream effectively delays the flow separation, which greatly improved the effectiveness of the flap section at low speed. Coupled with the effects of deflected slipstream, the aircraft can achieve greater short take-off and landing performance at lower speeds than the conventional take-off and landing and larger head-up torque. However, due to the propeller slipstream cannot effectively affect the rear wing, power lifting part is far from the focus. The focus moves forward in the short take-off and landing mode, aircraft static stability margin and aircraft stability both decreased. The relaxation of static stability control technology is thus needed.

Compared with the existing vertical / short take-off and landing aircraft, the joind aircraft has no tilting mechanism and no cyclic pitch mechanism. As the wings are interconnected and supported, the strength design requirements and the weight of the aircraft are greatly reduced,. Wing-lined aircraft are interconnected by front and rear wings, which helps to increase the structural rigidity of the wing and withstand greater wing loads and prevent wing flutter. Its aerodynamic characteristics often have a higher lift-drag ratio than the conventional layout, improving aircraft take-off and landing performance.

\section{Select the Flight Status}

In the flight performance of the aircraft, the lift-drag ratio is most closely related to the circling performance and cruising performance. This paper mainly studies the flight performance during the cruise phase. Therefore, several typical flight conditions are selected as the research focus. Because in addition to trim the aircraft using rear wing, we can also use the front wing flaps. The wing flaps trim participate in each state were thus analyzed. 
Table 1 Shape and Performance

\begin{tabular}{|c|c|}
\hline Shape and Performance & Data \\
\hline Empty weight $(\mathrm{kg})$ & 900 \\
\hline Maximum take-off weight $(\mathrm{kg})$ & 1500 \\
\hline Wing reference area $(\mathrm{m} 2)$ & 30 \\
\hline Wingspan $(\mathrm{m})$ & 11 \\
\hline Body length $(\mathrm{m})$ & 8.5 \\
\hline Design cruise speed $(\mathrm{km} / \mathrm{h})$ & 270 \\
\hline Design maximum speed $(\mathrm{km} / \mathrm{h})$ & 300 \\
\hline
\end{tabular}

Table 2 Flight Conditions

\begin{tabular}{|c|c|c|c|c|c|}
\hline Code & Status & Speed $(\mathrm{km} / \mathrm{h})$ & Flap & Lift coefficient & Height \\
\hline Case1 A & Take-off & 100 & $15^{\circ}$ & 1.0368 & 0 \\
\hline Case 1B & Short take-off & 66 & $60^{\circ}$ & 2.38 & 0 \\
\hline Case 2A & Slide down & 120 & $15^{\circ}$ & 0.882 & 2000 \\
\hline Case 2B & Slide down & 100 & $30^{\circ}$ & 1.1432 & 1000 \\
\hline Case 2C & Landing & 85 & $45^{\circ}$ & 1.435 & 0 \\
\hline Case 3A & Cruise & 225 & $0^{\circ}$ & 0.276 & 3000 \\
\hline Case 3B & Favourble speed & 136 & $15^{\circ}$ & 0.75 & 3000 \\
\hline Case 3C & Favourble speed & 126 & $30^{\circ}$ & 0.88 & 3000 \\
\hline Case 4A & Circling & 225 & $0^{\circ}$ & 0.414 & 3000 \\
\hline Case 4B & Circling & 225 & $15^{\circ}$ & 0.414 & 3000 \\
\hline Case 4C & Circling & 225 & $30^{\circ}$ & 0.414 & 3000 \\
\hline Case 5 & Maximum speed & 300 & $0^{\circ}$ & 0.1552 & 3000 \\
\hline
\end{tabular}

To assess the gains of relaxing longitudinal static stability obtained, we use five kinds of longitudinal static stability values. In this paper, we choose SLS1 as the general design index of the static stability aircraft, SLS2 SLS5 gradually abandon the natural stability and gradually relax the static stability. However, in short take-off and landing mode, due to the lifting module away from the focus position leads to the whole aircraft Aerodynamic focus moving forward, the longitudinal static stability is decreased.

Table 3 Static Stability Margin

\begin{tabular}{|c|c|c|c|c|c|}
\hline Code & SLS1 & SLS2 & SLS3 & SLS4 & SLS5 \\
\hline$\%$ & 40 & 30 & 20 & 10 & 0 \\
\hline
\end{tabular}

\section{Lift-Drag Ratio Gains}

The article defines the lift-drag ratio gain (LDRG) as: $\left(\mathrm{K}_{\text {trimmed }}-\mathrm{K}_{\text {untrimmed }}\right) \div \mathrm{K}_{\text {untrimmed }} \times 100 \%$ [5]

Table 4 LDRG of Joined-Wing Aircraft

\begin{tabular}{|c|c|c|c|c|c|}
\hline $\begin{array}{c}\text { Static stability } \\
\text { margin }\end{array}$ & SLS1 & SLS2 & SLS3 & SLS4 & SLS5 \\
\hline Case 1A & -0.53 & 0.66 & 1.85 & 3.04 & 4.22 \\
\hline Case 1B & 1.88 & 3.73 & 5.77 & 7.7 & 9.53 \\
\hline Case 2A & 1.43 & 2.39 & 3.37 & 4.32 & 5.28 \\
\hline Case 2B & 3.43 & 4.25 & 5.08 & 5.90 & 6.71 \\
\hline Case 2C & 2.24 & 3.53 & 4.91 & 6.22 & 7.54 \\
\hline Case 3A & -0.77 & -1.33 & -1.88 & -2.25 & -2.56 \\
\hline Case 3B & 1.62 & 1.96 & 2.30 & 2.62 & 2.93 \\
\hline Case 3C & 7.24 & 6.66 & 6.06 & 5.42 & 4.79 \\
\hline Case 4A & -0.15 & -1.00 & -1.80 & -2.33 & -2.70 \\
\hline Case 4B & 4.18 & 4.07 & 3.96 & 3.84 & 3.73 \\
\hline Case 4C & 12.02 & 14.35 & 16.68 & 18.98 & 21.27 \\
\hline Case 5 & -0.85 & -1.17 & -1.49 & -1.82 & -2.14 \\
\hline
\end{tabular}


Table 5 LDRG of Conventional Aircraft

\begin{tabular}{|c|c|c|c|c|c|}
\hline $\begin{array}{c}\text { Static stability } \\
\text { margin }\end{array}$ & SLS1 & SLS2 & SLS3 & SLS4 & SLS5 \\
\hline Case 1A & -12.25 & -11.26 & -10.31 & -9.49 & -8.74 \\
\hline Case 1B & - & - & - & - & - \\
\hline Case 2A & -13.60 & -12.71 & -11.84 & -10.95 & -10.03 \\
\hline Case 2B & -17.34 & -15.56 & -13.57 & -11.21 & -9.56 \\
\hline Case 2C & - & - & - & - & - \\
\hline Case 3A & -4.62 & -3.59 & -2.30 & -1.18 & 0.34 \\
\hline Case 3B & - & - & - & - & - \\
\hline Case 3C & - & - & - & - & - \\
\hline Case 4A & -11.09 & -10.15 & -9.24 & -8.64 & -7.76 \\
\hline Case 4B & - & - & - & - & - \\
\hline Case 4C & - & - & - & - & - \\
\hline Case 5 & -4.31 & -3.16 & -2.13 & -1.06 & 0.22 \\
\hline
\end{tabular}

\section{Lift-Drag Ratio Gain (LDRG) Analysis}

As can be seen from the above two tables:

Conventional aircraft in the longitudinal stability, the lift-drag ratio gains are negative, and increase after relaxing the longitudinal stability. In the case of a joined-wing aircraft flying at high speeds without flaps, the LDRG is negative, and decreases as the longitudinal stability decreases. When the aircraft uses wing flaps, front wing's lift increases greatly and lift-drag ratio gain improves significantly, but pattern is not obvious which is needed to study carefully

For the determination of the aircraft program, the LDRG of both cases can be quantified. The corresponding data in Table show the difference of LDRG of SLS 5(longitudinal static instability)and SLS1 (longitudinal static stability), which represent the LDRG caused by relaxation of longitudinal static stability.

Table 6 Profit of Relaxing Static Stability

\begin{tabular}{|c|c|c|}
\hline Code & A(joined-wing) & B(conventional) \\
\hline Case 1A & 4.75 & 3.51 \\
\hline Case 1B & 7.65 & - \\
\hline Case 2A & 3.85 & 3.57 \\
\hline Case 2B & 3.28 & 7.78 \\
\hline Case 2C & 5.3 & - \\
\hline Case 3A & -1.79 & 4.96 \\
\hline Case 3B & 1.31 & - \\
\hline Case 3C & -2.45 & - \\
\hline Case 4A & -2.55 & 3.33 \\
\hline Case 4B & -0.45 & - \\
\hline Case 4C & 9.25 & - \\
\hline Case 5 & -1.29 & 4.53 \\
\hline
\end{tabular}

As can be seen from the above table:

(1) In the discussions of the cases, the relaxation of the longitudinal static stability changes from SLS1 to SLS5, Scheme A's LDRG, in which case used trim flaps, is increased by $-2.55 \% \sim 7.65 \%$ than the non-trimmed case

(2) In the discussions of the cases, the relaxation of the longitudinal static stability changes from SLS1 to SLS5, Scheme B's LDRG, is increased by 3.33\% to 7 than the non-trimmed case. 
At a height of $3000 \mathrm{~m}$,with the aircraft flying stationarily, the relation between LDRG and speed shows below. The static stability changes from $40 \%$ to $0 \%$

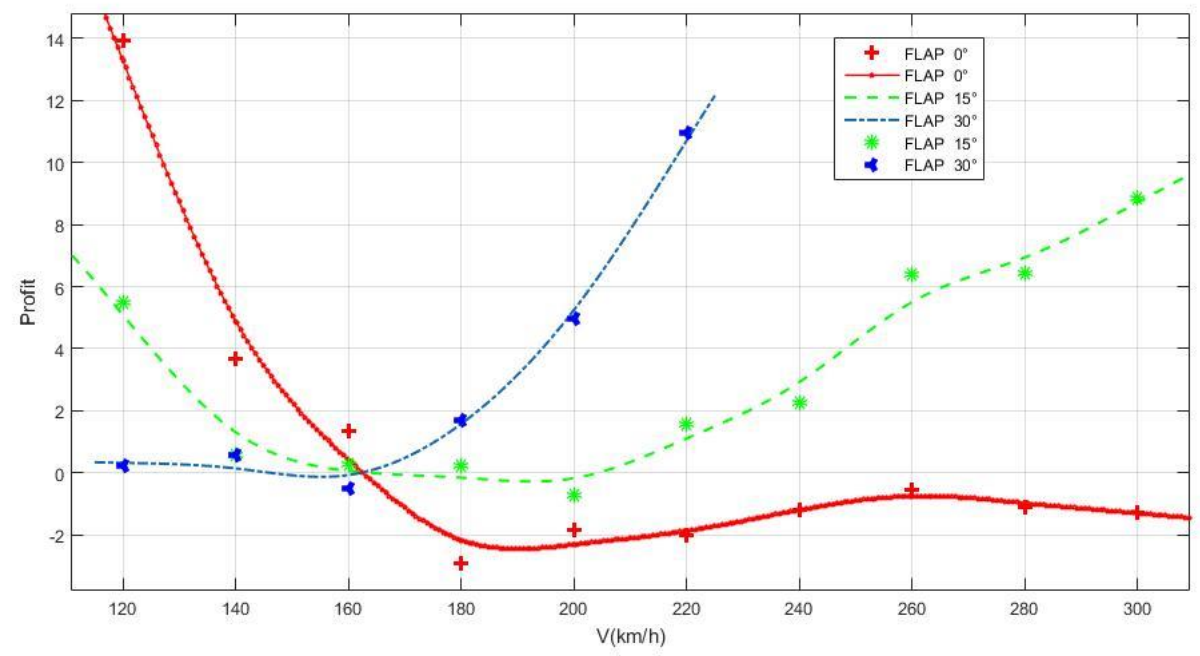

Fig. 2 The relationship between the LDRG and the speed

From the figure we can see:

(1) Without wing flaps, relaxing the static stability at low speeds gives a very large LDRG, but as the speed increases, the LDRG dropped to around $-2 \%$.

(2) With $15^{\circ}$ wing flaps, the LDRG decrease first and then increase with increasing speed.

(3) In the case of $30^{\circ}$ wing flaps, the benefits of relaxed static stability are small at low speeds but increase rapidly with increasing speeds, but because flaps are not suitable in this case and lift-drag ratio is too low to be taken as reference

(4) In the case of a $15^{\circ}$ wing flap, trim may be partially analogized to the front wing, which is very effective for wing aircraft lacking a control surface away from the centre of gravity. If the flaps of the front wings are made fully movable and trimmed, it is expected to achieve higher profits.

In Figure 2, we can see that the factors influencing the static stability of relaxation are very complicated. The best choice for the joined-wing aircraft is not when the static stability margin is at lowest. Then looking for a suitable static stability margin is a very important task, the following figure is maintained at $3000 \mathrm{~m}$ stationary flight, without the use of wing flaps, the relation between LDRG of 5 cases and flight speed is shown below:

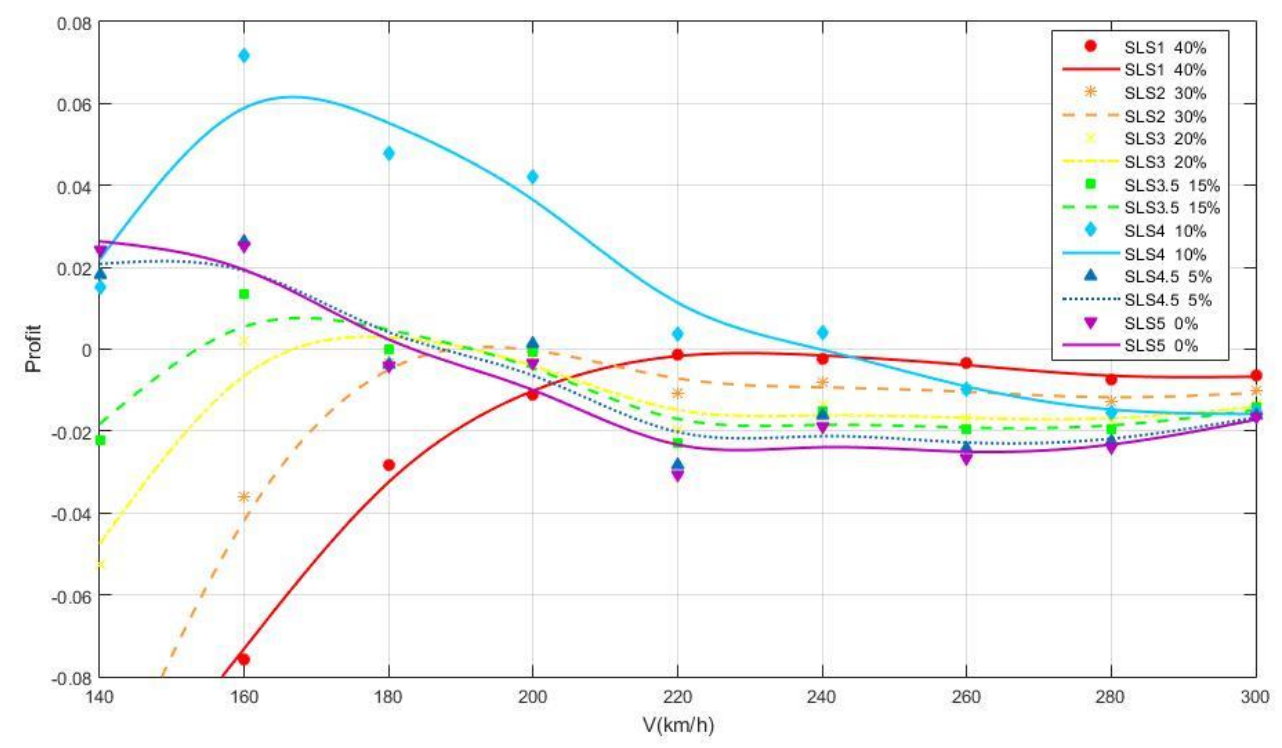

Fig. 3 The relationship between the LDRG and the speed

From the figure we can see: 
At a speed below $240 \mathrm{~km} / \mathrm{h}$, the trimmed LDRG of the $10 \%$ static margin is positive and yields the maximum. While $5 \%$ or $15 \%$ of the revenue has declined. For this joined-wing aircraft, the trimmed LDRG obtained by $10 \%$ of the static margin is higher than other cases.

\section{Summary}

In summary, relaxing the longitudinal static stability is an important part of active control technology, which can increase the lift, reduce drag and improve the range of conventional aircraft. But when it is applied to the joined-wing aircraft, although the lift-drag ratio at low speed can be significantly increased, the benefits are caused by multiple factors, in which case we cannot blindly reduce static stability margin.

\section{References}

[1].E. Livne. Aeroelasticity of joined-wing airplane configurations - Past work and future challenges a survey $[\mathrm{M}], 2001$

[2]. FENG Xiao-gang, LI Yan, CUI Yong-qing. Research on relaxed static stability of civil aircraft [J]. Electronic Design Engineering. 2013. 21(19): 118-119

[3].William Blake,James Simon. Tools for rapid analysis of aircraft and missile aerodynamics [M], 2013

[4].GUO Wei-gang, YU Xiong-qing. Discussion on the layout characteristics of joined-wing aircraft [J].Journal of Naval Aeronautical Engineering Institute. 2005. 20(2): 201-204

[5].Zheng sui,Zhan jing-xia,Cao Yuan. Effect of relaxed longitudinal static stability on lift-to-drag ratio of aircraft configuration [J]. Journal of Nanjing University of Aeronautics \& Astronautics. 2008 (04): 556-560 